\title{
PERSPECTIVE
}

\section{Primary Care: the New Frontier for Reducing Readmissions}

\author{
Sonali Saluja, MD, MPH' , Michael Hochman, MD, MPH' , Angel Bourgoin, $P h D^{2}$, and \\ James Maxwell, $P h D^{2}$
}

'The Gehr Family Center for Health Systems Science \& Innovation, Keck Medicine of USC, Los Angeles, CA, USA; ${ }^{2}$ John Snow, Inc., Boston, MA, USA.

To date, efforts to reduce hospital readmissions have centered largely on hospitals. In a recently published environmental scan, we examined the literature focusing on primary care-based efforts to reduce readmissions. While rigorous studies on interventions arising from primary care are limited, we found that multi-component care transitions programs that are initiated early in the hospitalization and are part of broader primary care practice transformation appear most promising. However, policy changes are necessary to spur innovation and support effective primary care-led transitions interventions. Though more rigorous research is needed, our findings suggest that primary care can and should lead future efforts for reducing hospital readmissions.

KEY WORDS: primary care; health care delivery; primary care redesign.

$\mathrm{J}$ Gen Intern Med 34(12):2894-7

DOI: $10.1007 / \mathrm{s} 11606-019-05428-2$

๑) Society of General Internal Medicine 2019

$\mathrm{H}$ igh rates of hospital readmissions are a persistent problem in the USA. Widespread efforts to implement hospital-based care transitions programs, such as RED (Reengineered Discharge) and others, have garnered considerable attention and have yielded favorable results over the past several years. ${ }^{1-4}$ While hospitals continue to refine their readmission reduction efforts, their ability to control what happens after discharge and outside of their walls remains limited. With recent estimates suggesting that approximately a quarter of hospital readmissions may be avoidable, it is essential for us to pursue new approaches to address gaps in the care transitions process. $^{5}$

One area ripe for exploration is primary care-based initiatives, which to date have received less emphasis. Many successful hospital-based programs involve the coordination of post-discharge ambulatory services, but outpatient clinics may play only a passive and limited role in the process. Given that the core components of primary care, as described by Barbara Starfield in her seminal book, are contact accessibility, coordination, comprehensiveness, and continuity, it follows that

\section{Prior Presentations None}

Received August 22, 2018

Accepted September 13, 2019

Published online October 16, 2019 primary care ought to serve a more prominent role in care transition efforts. ${ }^{6}$ Yet there are few concerted efforts underway to develop, implement, and assess primary care-based transitions programs.

In a recently published environmental scan commissioned by the Agency for Healthcare Research and Quality (AHRQ), we assessed the current state of the literature on primary carebased care transitions programs. ${ }^{7}$ We identified numerous peer-reviewed and non-peer-reviewed studies ranging from narrow interventions to more comprehensive multicomponent initiatives. While some of the included studies had methodological limitations (there were few rigorous controlled analyses), collectively, they shed light on the types of interventions that are likely to be successful, revealing practical considerations and policy changes needed for making these initiatives sustainable. In this piece, we summarize insights from the environmental scan and make a case for an enhanced and expanded role for primary care in the care transitions process.

\section{BUNDLED VERSUS SINGLE-COMPONENT INTERVEN- TIONS ARE MORE LIKELY TO SUCCEED}

First, we found that multi-component, or "bundled," programs addressing multiple care transitions challenges that patients and providers face were some of the most successful. These programs often utilize clinic-based care managers and include several distinct processes such as close follow-up with a provider, post-discharge phone calls, medication reconciliation, addressing transportation barriers, and scheduling follow-up with social workers and other critical primary care team members. ${ }^{8-14}$ Conversely, studies examining the impact of more narrowly focused programs, such as implementing automated admission notifications, medication reconciliations, or post-discharge phone calls alone, were less encouraging.

Second, primary care practices with bundled transitions programs tended to be initiated early in the patient's hospital course. While primary care notifications for patient hospitalizations alone were not enough to reduce readmissions, hospitalization alerts were frequently an important component of successful interventions. These bundled programs often "reached in" to patients in the hospital prior to discharge - either to assess the patient's biopsychosocial needs, obtain accurate patient or caregiver contact 
information, set up follow-up appointments, communicate with the inpatient care team, or assist with developing discharge instructions. ${ }^{10-15}$

Third, the vast majority of bundled primary care-based interventions described in the literature occurred either in primary care practices that were affiliated with hospitals or in settings in which a third-party payer initiated the program. Evidence is lacking as to whether small, independent practices have the capacity to implement multifaceted interventions without support from an affiliated hospital or third-party payer.

Lastly, some of the most promising transitional care interventions occurred in the setting of larger scale practice transformation, such as those guided by the Primary Care Medical Home framework. The success of transitions programs in a primary care medical home setting is perhaps not surprising given that care coordination is a key building block in the medical home models described by Bodenheimer and Wagner. ${ }^{16,}{ }^{17}$ We also suspect that these broad clinic "redesign" efforts may have had a synergistic effect with the transitional care interventions, leading to a more pronounced effect on readmission rates.

\section{INNOVATION IN PRIMARY CARE REQUIRES SYSTEM- WIDE REFORMS}

Our findings suggest a number of changes in clinical practice and policy that could help promote engagement by primary care practices in the care transitions process.

First, poor communication between hospitals and primary care clinicians may impede the development of primary carebased care transitions programs. Many of the articles on care transitions that we reviewed highlighted challenges with care coordination. ${ }^{18-20}$ Primary care-based efforts might be more effective if they align with hospital-based interventions, with well-defined roles and accountability throughout the care transitions process. ${ }^{8,10,11}$ The existence of integrated or compatible electronic health records for all clinics in the system may facilitate collaboration but is insufficient in isolation. ${ }^{21}$

Second, providing adequate support, resources, and compensation for primary care clinics to lead care transitions efforts is imperative. Several of the successful primary carebased transitions programs we reviewed required significant investment (in many cases from health plans) in practice innovations such as home visits and the hiring of care coordinators and social workers (who typically cannot bill for their services). ${ }^{22-24}$ Though many practices lack the resources to invest in such team members, these groups might be able to hire necessary personnel by pooling their resources. A couple of years ago, the Centers for Medicare and Medicaid Services launched fee-for-service programs that reimburse primary care providers for transitional care and chronic care management. ${ }^{25,}{ }^{26}$ While these programs are a step in the right direction, they have limitations. The recently evaluated Comprehensive Primary Care Initiative, which focused on clinics serving fee-for-service Medicare beneficiaries, resulted in improved coordination of care transitions and reduced emergency department visits, but failed to reduce readmissions or total cost of care. ${ }^{27}$ Fee-for-service payments alone may be insufficient to support the comprehensive, clinic-level transformation that is often required to reduce readmissions. ${ }^{28}$

Many experts have proposed alternative payment strategies, particularly value-based payments, to improve outcomes among primary care providers. Pay-for-performance programs and capitated risk-bearing payment models might better incentivize primary care practices to invest in care transitions activities, enabling primary care providers to accept increasing risk and accountability for the populations they serve. To date, evidence on value-based payment models in primary care shows modest benefits with respect to some process measures, while demonstrating a benefit with respect to health outcomes has thus far proven difficult. ${ }^{29}$ Some cost savings, however, have been suggested in physician-led models. ${ }^{30}$ Furthermore primary care providers may be reluctant to accept risk for variables outside of their control - notably care that patients receive in the hospital as well as social and environmental health determinants (factors that are generally not addressed by the health care system, at least not in the USA). Next year, the Centers for Medicare and Medicaid Services will be launching Primary Care First, a program designed to encourage primary care to reduce health care utilization and increase care quality through flexibility, enhanced revenue and valuebased reimbursement. ${ }^{31}$ Examining the implementation and impact of this program could enhance our understanding of the effectiveness of value-based payment programs in enhancing care coordination and reducing avoidable readmissions.

Finally, our review for AHRQ focused on traditional primary care approaches for reducing readmissions. However, it is important to acknowledge a growing consensus among policy experts that social determinants of health play a significant role in overall health outcomes including hospital readmission. ${ }^{32}$ Primary care clinicians have long understood the value of working with organizations that utilize community health workers and other social service agencies to help patients facing poor housing, food insecurity, and social isolation. ${ }^{33,} 34$ The review found only limited research on primary care collaboration with community health organizations during the care transitions process. Understanding how primary care could effectively partner with programs that address socioeconomic challenges offers an intuitive approach for preventing readmissions and improving quality of care.

\section{PRIORITIZING PRIMARY CARE INNOVATION IS ESSENTIAL FOR REDUCING READMISSIONS}

While hospital-based efforts have modestly lowered overall readmission rates in the USA, primary care clinics must take on a central role in the care transitions process to achieve greater impact. ${ }^{35}$ In fact, we believe that primary care 
clinicians and teams should "own" this process. Our review reveals several ways in which primary care can take on this central role. First, care transitions efforts should include bundled or multifaceted interventions that address gaps on several fronts, ranging from medication management and discharge alerts to patient education and home care, depending on patient needs. These efforts may be most effective when implemented early in the hospital course and within the context of large-scale primary care transformation. Second, such efforts should be aligned with hospital-based efforts. This means primary care practices should consider developing relationships with hospitals frequented by their patients, perhaps through a formalized "community contract", with a mutual goal of sharing data, identifying high-risk patients, communicating during a patient's hospitalization, and coordinating care transitions processes. ${ }^{36}$ Third, and most importantly, to study, implement, and expand care transitions programs, health systems leaders and policymakers must invest in primary care staff and infrastructure that will enable primary care clinics to take the lead.

Our review of the body of evidence leads us to believe that primary care represents the "next frontier" in efforts to reduce readmissions. It is time for policymakers and other key stakeholders to provide the resources, incentives, and authority necessary for primary care clinics to take charge of the care transitions process.

Corresponding Author: Sonali Saluja, MD, MPH; The Gehr Family Center for Health Systems Science \& Innovation Keck Medicine of USC, 2020 Zonal Avenue, 323 IRD, Los Angeles, CA 90033, USA (e-mail: sonali.saluja@med.usc.edu).

Funding Information The Environmental Scan was funded under a contract, "The Re-engineered Visit for Primary Care (AHRQ REV)," contract number HHSP233201500019I/HHSP23337002T from the Agency for Healthcare Research and Quality (AHRQ), U.S. Department of Health and Human Services (HHS).

\section{Compliance with Ethical Standards:}

Conflict of Interest: The authors declare that they do not have a conflict of interest.

Disclaimer: The findings and conclusions in this document are those of the authors, who are responsible for its content, and do not necessarily represent the views of AHRQ. No statement in this document should be construed as an official position of AHRQ or HHS.

\section{REFERENCES}

1. Jack B, Chetty VK, Anthony D et al. A Reengineered Hospital Discharge Program to Decrease Rehospitalization. Ann Intern Med 2009; 150(3): 178.

2. Coleman EA, Parry C, Chalmers S, Min S. The Care Transitions Intervention: Results of a Randomized Controlled Trial. Arch Intern Med 2006; 166(17): 1822-1828.

3. Hansen LO, Greenwald JL, Budnitz T, et al. Project BOOST: effectiveness of a multihospital effort to reduce rehospitalization. J Hosp Med 2013;8(8):421-427.
4. Naylor MD, Aiken LH, Kurtzman ET, Olds DM, Hirschman KB. The care span: The importance of transitional care in achieving health reform. Health Aff (Millwood) 2011;30(4):746-754.

5. Auerbach A, Kripalani S, Vasilevskis E, et al. Preventability and Causes of Readmissions in a National Cohort of General Medicine Patients. JAMA Intern Med 2016;176(4):484.

6. Starfield B. Primary care: concept, evaluation, and policy. New York: Oxford University Press; 1992.

7. Hochman M, Bourgoin A, Saluja S, et al. Environmental Scan of Primary Care-Based Efforts To Reduce Readmissions. Rockville, MD: Agency for Healthcare Research and Quality; March 2019. AHRQ Publication No. 18(19)-0055-EF

8. Cavanaugh J, Jones C, Embree G, et al. Implementation Science Workshop: Primary Care-Based Multidisciplinary Readmission Prevention Program. J Gen Intern Med 2014;29(5):798-804.

9. Farrell T, Tomoaia-Cotisel A, Scammon, D, et al. Impact of an Integrated Transition Management Program in Primary Care on Hospital Readmissions. J Healthc Qual 2015;37(1):81-92.

10. White B, Carney P, Flynn J, Marino M, Fields S. Reducing hospital readmissions through primary care practice transformation. J Fam Pract 2014;63(2):67-73.

11. Balaban R, Weissman J, Samuel P, Woolhandler S. Redefining and Redesigning Hospital Discharge to Enhance Patient Care: A Randomized Controlled Study. J Gen Intern Med 2008;23(8):1228-1233.

12. Stranges $P$, Marshall V, Walker $P$, et al. A multidisciplinary intervention for reducing readmissions among older adults in a patient-centered medical home. Am J Manag Care 2014;21(2):106-13.

13. Foltz C, Lawrence S, Biery N, et al. Supporting Primary Care PatientCentered Medical Homes with Community Care Teams: Findings from a Pilot Study. J Clin Outcomes Manag 2014;21(8):352-361.

14. Takahashi P, Naessens J, Peterson S, et al. Short-term and Long-term Effectiveness of a Post-hospital Care Transitions Program in an Older, Medically Complex Population Healthc 2016;4(1):30-35.

15. Boyd CM, Shadmi E, Conwell LJ, et al. A pilot test of the effect of guided care on the quality of primary care experiences for multimorbid older adults. J Gen Intern Med 2008;23(5):536-42.

16. Wagner E, Sandhu N, Coleman K, et al. Improving care coordination in primary care. Med Care 2014;52(11 Suppl 4):S33-8.

17. Bodenheimer T, Ghorob A, Willard-Grace R, Grumbach K. The 10 Building Blocks of High-Performing Primary Care. Ann Fam Med 2014;12(2):166-171.

18. Arora VM, Prochaska ML, Farnan JM, et al. Problems after Discharge and Understanding of Communication with their Primary Care Physicians among Hospitalized Seniors: A mixed methods study. J Hosp Med 2010; 5 (7):385-91.

19. Cain C, Neuwirth E, Bellows J, Zuber C, Green J. Patient Experiences of Transitioning from Hospital to Home: An Ethnographic Quality Improvement Project. J Hosp Med 2012;7(5):382-387.

20. Ackerman S, Gleason N, Monacelli J, et al. When to Repatriate? Clinicians' Perspectives on the Transfer of Patient Management from Specialty to Primary Care. J Gen Intern Med 2014;29(10):1355-1361.

21. Gurwitz J, Field T, Ogarek J, et al. An Electronic Health Record-Based Intervention to Increase Follow-Up Office Visits and Decrease Rehospitalization in Older Adults. J Am Geriatr Soc 2014;62(5):865-871.

22. Rosenberg C, Peele P, Keyser D, McAnallen S, Holder D. Results From A Patient-Centered Medical Home Pilot At UPMC Health Plan Hold Lessons For Broader Adoption of The Model. Health Aff (Milwood) 2012;31(11):2423-2431.

23. Schraeder C, Fraser C, Clark I, et al. Evaluation of a Primary Care Nurse Case Management Intervention for Chronically Ill Community Dwelling Older People. J Clin Nurs 2008;17(11c):407-417.

24. Jackson CT, Trygstad TK, DeWalt DA, DuBard CA. Transitional Care Cut Hospital Readmissions for North Carolina Medicaid Patients with Complex Chronic Conditions. Health Aff (Milwood) 2013;32(8):1407-1415.

25. Centers for Medicare and Medicaid Services. Medicare Proposes Substantial Improvements to Paying for Care Coordination and Planning, Primary Care, and Mental Health in Doctor Payment Rule. Available at: https://www.cms.gov/newsroom/press-releases/medicare-proposessubstantial-improvements-paying-care-coordination-and-planning-primary-care-and. Published July 2016. Accessed August 27, 2019.

26. Centers for Medicare and Medicaid Services. Chronic Care Management Services. Available at: https://www.cms.gov/Outreach-and-Education/ Medicare-Learning-Network-MLN/MLNProducts / Downloads / ChronicCareManagement.pdf. Published December 2016. Accessed August 27,2019 
27. Peikes D, Dale S, Ghosh A, Taylor EF, Swankoski K, O’Malley AS, Day TJ, Duda N, Singh P, Anglin G, Sessums LL, Brown RS. The Comprehensive Primary Care Initiative: Effects On Spending, Quality, Patients And Physicians, Health Aff 2018;37(6):890-899.

28. Basu S, Phillips RS, Song Z, Landon BE, Bitton A. Effects of New Funding Models for Patient-Centered Medical Homes on Primary Care Practice Finances and Services: Results of a Microsimulation Model. Ann Fam Med 2016;14(5):404-414

29. Mendelson A, Kondo K, Damberg C, et al. The Effects of Pay-forPerformance Programs on Health, Health Care Use, and Processes of Care: A Systematic Review. Ann Intern Med 2017;166(5):341.

30. Robinson JC, Miller K. Total Expenditures per Patient in Hospital-Owned and Physicians-Owned Physician Organizations in California. JAMA. 2014; 312(16): 1663-1669.

31. Commins J. CMS Launches Value-Based Primary Care Initiative with Downside Risk. Health Leaders. Available at: https:// www.healthleadersmedia.com/finance/cms-launches-value-based-primary-care-initiative-downside-risk. Published April 2019. Accessed August 27, 2019.

32. Barnett ML, Hsu J, McWilliams JM. Patient Characteristics and Differences in Hospital Readmission Rates. JAMA Intern Med 2015;175(11):1803.
33. Kangovi S, Grande D, Trinh-Shevrin C. From Rhetoric to Reality Community Health Workers in Post-Reform U.S. Health Care. N Engl J Med 2015;372(24):2277-2279.

34. Carlson S, Keith-Jennings B. SNAP is Linked with Improved Nutritional Outcomes and Lower Health Care Costs. Center on Budget and Policy Priorities. Available at: https://www.cbpp.org/research/food-assistance/ snap-is-linked-with-improved-nutritional-outcomes-and-lower-healthcare. Published January 2018. Accessed August 27, 2019.

35. Zuckerman RB, Sheingold SH, Orav EJ, Ruhter J, Epstein AM. Readmissions, Observation, and the Hospital Readmissions Reduction Program. N Engl J Med 2016;374(16):1543-1551.

36. Jones C, Vu M, O’Donnell C, et al. A failure to communicate: a qualitative exploration of care coordination between hospitalists and primary care providers around patient hospitalizations. J Gen Intern Med 2014;30 (4):417-24.

Publisher's Note Springer Nature remains neutral with regard to jurisdictional claims in published maps and institutional affiliations. 